\title{
"AVALIAÇÃO ESCOLAR": TERMO, CONCEITO E VISÃO DE MUNDO EM PORTUGUÊS E EM MUNDURUKÚ (TUPÍ)
}

\author{
("School evaluation": term, concept, world view in Portuguese \\ and Munduruku - Tupian language)
}

Dioney M. Gomes ${ }^{1}$

Tânia Borges Ferreira ${ }^{2}$

\section{ABSTRACT}

This paper is about the technical term "school evaluation" in the context of bilingualism education and the learning of Portuguese second language by the Brazilian native people Munduruku (Pará). We start with a historical panorama about the school evaluation in Brazil to understand the comprehension about the term and its changes in time. Thus, it was possible to identify what theoretical principles exist in the basis of definitions about "school evaluation" in general and in specialized dictionaries nowadays. Following that, we present the concept and the view about the process of school evaluation for Munduruku people. Our major aim is to justify the choices that we did when we proposed the bilingual entry "school evaluation" in the Dicionário Terminológico Escolar Português-Mundurukú/ Mundurukú-Português (apresentar entre parênteses a tradução para o ingles), that we are writing. The construction of this dictionnary is based on Communicative Theory of Terminology (CTT), Text Linguistics and Corpus Linguistics (Bevilacqua (1998), Boulanger (1995), Cabré (1998; 1999a, b, c), Carvalho (2005), Gemar (1991), Hoffmann (1998), Kokourek (1991), L'Homme (2004), Sardinha (2004) and others).

1. Doutor em Linguística, professor adjunto 3 do Departamento de Linguística, Português e Línguas Clássicas, e pesquisador permanente do Programa de PósGraduação em Linguística (Mestrado e Doutorado) da Universidade de Brasília.

2. Licenciada em Letras (Língua Portuguesa e Respectivas Literaturas) e mestranda do Programa de Pós-Graduação em Linguística da Universidade de Brasília. 
Keywords: school evaluation, terminology, school terminological dictionary, bilingual education, Munduruku language, Portuguese language, believes.

\section{RESUMO}

O presente artigo traz uma reflexão sobre o termo avaliação escolar no contexto de educação bilíngue e ensino de Português como segunda língua entre índios/as brasileiros/as da etnia Mundurukú (Pará). Partimos de um panorama histórico da avaliação educacional brasileira para entender as crenças criadas acerca do termo e suas transformações no decorrer do tempo. Assim, foi possivel identificar quais linhas teóricas estão na base das definições de avaliação nos dicionários gerais e especializados da atualidade. Após isso, apresentamos o conceito e a visão de mundo relativo a processo de avaliação escolar entre os/as índios/as Mundurukú. O nosso objetivo maior é justificar as escolhas que fizemos ao propor um verbete bilíngue ao termo avaliação escolar no Dicionário Terminológico Escolar Português - Mundurukú/ Mundurukú - Português, que ora escrevemos. A construção do dicionário está baseada na Teoria Comunicativa da Terminologia (TCT), na Linguística Textual e na Linguística de Corpus (Bevilacqua (1998), Boulanger (1995), Cabré (1998; 1999a, b, c), Carvalho (2005), Gemar (1991), Hoffmann (1998), Kokourek (1991), L'Homme (2004), Sardinha (2004) e outros).

Palavras-chave: Avaliação escolar, terminologia, dicionário terminológico escolar, educação bilíngue, língua mundurukú, língua portuguesa, crenças.

\section{Introdução}

O presente artigo traz uma reflexão sobre o termo avaliação escolar com o objetivo de compreendê-lo melhor e justificar as nossas escolhas ao defini-lo no Dicionário Terminológico Escolar Português-Mundurukú/ Mundurukú-Português. Para isso, buscamos compreender o termo, o conceito e a visão de mundo relativos ao processo de avaliação escolar, tanto na sociedade brasileira em geral quanto na sociedade Mundurukú em particular, para, então, fazermos uma proposta de verbete bilíngue.

Este trabalho está dividido em seis partes. A primeira é destinada a um breve panorama da história da educação brasileira 
com foco na avaliação, para entender qual a visão de mundo que a sociedade brasileira criou acerca do termo, e como essa visão está sendo transformada no decorrer da nossa história até chegar nas atuais discussões sobre avaliação escolar. Na segunda parte, são discutidas as definições do termo nos dicionários de língua comum e nos dicionários especializados da área de educação, a fim de analisar quais linhas teóricas estão na base dessas definições e, por consequência, a visão de mundo nelas embutida. A terceira parte aborda a educação e a avaliação escolar na comunidade indígena Mundurukú, com o intuito de conhecer a realidade escolar Mundurukú, uma vez que o públicoalvo do dicionário são os/as alunos/as Mundurukú do ensino médio. A quarta parte apresenta o projeto do Dicionário Terminológico Escolar Português-Mundurukú/ Mundurukú-Português. A quinta parte analisa o termo na visão de mundo Mundurukú. A sexta parte discute, analisa e reflete sobre as nossas escolhas feitas ao definir o termo no dicionário, respeitando-se as visões de mundo das duas sociedades. $\mathrm{O}$ artigo é encerrado com as considerações finais acerca do termo.

\section{História da educação brasileira e da avaliação}

Nesta seção, será abordada brevemente a história da educação brasileira com o objetivo de identificar as escolhas feitas em cada período a respeito da prática escolar da avaliação.

A educação escolar brasileira teve início no século XVI com a vinda do Padre Manoel da Nóbrega e de mais dois jesuítas, tornandose eles os primeiros professores e fundadores das primeiras escolas. O plano de estudos de Nóbrega estava voltado em nível básico para alfabetização, ensino de português e de doutrina cristã; no nível seguinte, o/a aluno/a estudava música instrumental e canto orfeônico; terminando essa fase, ele/a poderia finalizar os estudos com aprendizado profissional voltado para a área da agricultura ou continuar os estudos nas aulas de gramática para completar os estudos na Europa (GHIRALDELLI, 2009). Ribeiro (1992:23) afirma que esse plano de estudo "não tinha, inicialmente, de modo explícito, a 
intenção de fazer com que o ensino profissional atendesse à população indígena e o outro à população 'branca' exclusivamente", pois houve tentativas de recrutar índios/as para seguir as vocações sacerdotais.

Segundo Ghiraldelli (2009), com a chegada de outros grupos de jesuítas ao Brasil e sua integração aos projetos educativos, no fim do século XVI, a pedagogia utilizada nos colégios evoluiu do plano de estudos de Nóbrega para o uso do Ratio Studiorum - plano de estudos com curso básico de humanidades, filosofia e teologia -, com a finalização dos estudos na Europa para a elite. De acordo com Ribeiro (1992), já havia uma distinção clara entre a educação de índios/as de instrução e catequese, e a educação básica da elite, tendo, assim, grande influência na sociedade brasileira.

Durante os séculos XVI e XVII, os jesuítas mantiveram praticamente o monopólio do ensino escolar brasileiro, porém não existia de fato um modo de avaliação.. Segundo Aranha (1989), o ensino jesuítico era baseado na memorização por meio de exercícios de fixação e repetição, fazendo que os/as melhores alunos/as auxiliassem o/a professor/a a tomar as lições; desse modo, as classes inferiores repetiam as lições aos sábados (as sabatinas). Sobre a relação entre avaliação e educação no período jesuítico, Comis (2006:137) afirma que: "a avaliação no ensino jesuítico tinha (...) a função de disciplinar os alunos, e a educação era diferenciada para a elite e para as classes populares". A avaliação tinha um caráter punitivo e media a capacidade de memorização e de repetição, sem reflexão.

No século XVIII, Marquês de Pombal, Ministro do Estado em Portugal, cria reformas, buscando transformações econômicas, políticas e culturais. Com a expulsão dos jesuítas de Portugal e de suas colônias, no Brasil, criam-se as aulas-régias, aulas avulsas de latim, grego, filosofia e retórica, desvinculadas em certa medida das ordens religiosas.

Com a vinda da corte portuguesa para o Brasil no início do século XIX, foram criados cursos superiores e técnicos. Nesse período, o ensino brasileiro sofreu grandes mudanças. Com o Império, o ensino foi estruturado em nível primário, voltado para a alfabetização, e nível secundário, que manteve o esquema das aulas-régias, pois, 
apenas com a Constituição de 1824 é que o ensino pela primeira vez foi regulamentado. Na segunda metade do século XIX, surgiram escolas particulares, a maioria católicas, e surgiram também escolas protestantes e positivistas. De acordo com Comis (2006, p.137), "a avaliação, durante o Império, nas escolas primárias públicas, era assistemática e precária, uma vez que os alunos não eram examinados regularmente”. Embora não seja explícito o modo como era realizada essa avaliação, percebemos que ela não ocupava um lugar de destaque nesse período, fato tão ruim quanto a avaliação punitiva e mnemônica do período anterior.

Na República, o ensino aderiu a uma orientação positivista, defendendo uma educação anuladora das tensões sociais. Comis (2006:137) afirma que "foi no período republicano que o ensino se instituiu como atividade sistemática e contínua, submetido a uma série de burocratizações, em que os exames compreendiam provas orais, escritas e práticas”. Ainda segundo essa autora, a avaliação nesse período passa a ser normatizada, padronizada e ritualizada. Isso contribui para a manutenção das desigualdades sociais, elevando os índices de reprovação.

Portanto, desde a colonização até o início do século XX, o ensino seguia a tendência tradicional que, segundo Libâneo (1994), tem como característica a atividade de ensinar centrada na figura do/a professor/a, que utiliza como principal recurso didático a fala por meio de aulas expositivas, supondo que ouvindo e fazendo exercícios repetitivos os/ as alunos/as gravem o conteúdo para reproduzi-lo nas provas escritas ou orais que eram os meios de avaliação. Assim, os conteúdos eram transmitidos de modo separado da experiência, e os pressupostos de aprendizagem eram baseados na recepção, repetição e memorização, sendo a avaliação escolar um instrumento para medir tudo isso. Comis (2006:138) ressalta que, no ensino tradicional, "a avaliação desempenha papel fundamental para medir a quantidade de conhecimento assimilado pelos alunos e, por isso, foi ganhando cada vez mais espaço e assumindo uma função definida na prática educacional”.

Nas primeiras décadas do século XX, com o ensino voltado para o pensamento positivista, o surgimento de novas ciências e a 
propagação do método científico, a avaliação passou a estar associada à psicometria, teoria da inteligência baseada nas propriedades inatas e fixas do ser humano e na possibilidade de medi-las por meio de instrumentos. Nesse período, não se distinguia avaliação de medida, e a grande preocupação de estudiosos/as estava voltada para a elaboração de instrumentos e testes para verificar o rendimento escolar (SOUZA, 1995). A função do/a avaliador/a era técnica, e os exames e testes eram indispensáveis para classificar os/as alunos/as.

Na década de 1930, surge no Brasil um movimento contra o ensino tradicional, com a publicação, em 1932, do Manifesto dos Pioneiros da Educação Nova, que abordava questões relacionadas à laicidade, gratuidade, obrigatoriedade. Esse movimento apresentava como ponto renovador a ideia do/a professor/a conhecer o/a educando/a, transferindo para a criança o eixo da escola. Desse modo, a Escola Nova tem como centro de sua atividade escolar o/a aluno/a ativo/a, e o/a professor/a passa a ser um/a auxiliador/a. Essa tendência valoriza mais o processo de aprendizagem, visando à formação do pensamento autônomo por meio de pesquisa e de investigação. Para Comis (2006), a avaliação aí enfatiza o processo de aprendizagem, avaliando o/a aluno/a como um todo. Mas, segundo Libâneo (1994: 66), "na hora de comprovar os resultados de ensino e da aprendizagem, pediam matéria decorada, da mesma forma que se faz no ensino tradicional”. Isso se deu por falta de conhecimento, por parte dos/as professores/as, das bases teóricas, condições de materiais e exigências do programa oficial, ficando, na prática, apenas alguns métodos e técnicas da proposta escolanovista.

Com a Constituição de 1934, foi garantida a gratuidade e a obrigatoriedade do ensino primário integral, mas, com o Estado Novo e sua nova constituição em 1937, esses direitos foram maculados. Após a Constituição de 1946, houve a tentativa de criação da primeira Lei de Diretrizes e Bases da Educação (LDB) que teve o seu projeto encaminhado ao congresso em 1948 e arquivado em 1949. Apenas em 1961, esse projeto foi sancionado pelo presidente da República, depois de inúmeras modificações, não condizendo mais com a realidade brasileira da época. Nesse período, 
Paulo Freire já estava em voga com a sua pedagogia libertadora, a qual buscava conscientizar o/a brasileiro/a, tornando-o/a sujeito da história, refletindo sobre a ideia de que a transformação surgiria da emancipação das classes populares (GHIRALDELLI, 2009). Segundo Comis (2006), a avaliação na pedagogia libertadora era voltada para o domínio crítico dos conteúdos para formar cidadãos/ ãs que transformem a realidade, porém não existia uma metodologia clara para esse tipo de avaliação.

O golpe militar de 1964 fez que fossem mudadas outra vez as propostas educacionais, e para a pior. Nesse período, a população brasileira já era de maioria urbana, houve também a chamada democratização do ensino e o surgimento de uma nova LDB em 1971. Durante esse período, o foco da educação se deu no ensino profissionalizante e, como vivíamos uma ditadura, a pedagogia que melhor se enquadrava era a tecnicista. Segundo Libâneo (1994), ela era inspirada no behaviorismo e tinha um caráter meramente instrumental, sendo o ensino muito técnico, resultando na fórmula: objetivos, conteúdos, estratégias e avaliação. A avaliação, segundo Comis (2006), era feita por meio de provas objetivas, tornando a avaliação quantitativa, impessoal, aleatória e passiva.

As lutas sociais da década de 1970 viabilizaram espaço para novas discussões sobre a educação, voltando às tendências pedagógicas de cunho progressista. Além da pedagogia libertadora, surgiu, nesse momento, a pedagogia libertária - centrada na ideia de que a escola deve ser um instrumento de conscientização e organização política - e surgiu também a pedagogia crítico-social dos conteúdos, segundo a qual a escola deve cumprir a sua função social e política, atribuindo ao ensino o papel de oferecer ao/à aluno/a o domínio de conteúdos científicos (LIBÂNEO, 1994).

Ao falar da avaliação escolar sob o prisma das tendências liberais (tendência tradicional, tendência escolanovista e tendência tecnicista), Luckesi (2008:32) afirma que "a prática da avaliação escolar, dentro do modelo liberal conservador, terá de, obrigatoriamente, ser autoritária, pois esse caráter pertence à essência dessa perspectiva de sociedade, que exige controle e enquadramento 
dos indivíduos nos parâmetros previamente estabelecidos (...)". Já ao discutir a avaliação escolar nas tendências progressistas (tendências libertadora, libertária e crítico-social dos conteúdos), ele diz que "a prática da avaliação nas pedagogias preocupadas com a transformação deverá estar atenta aos modos de superação do autoritarismo e ao estabelecimento da autonomia do educando, pois o novo modelo social exige a participação democrática de todos". (LUCKESI, 2008:32)

Com o fim da ditadura, ampliaram-se os debates sobre a educação e as formas como são realizadas as avaliações escolares. De acordo com Luckesi (2008:23): "Ao longo da história (...), a avaliação da aprendizagem escolar (...) foi se tornando um fetiche (...), uma 'entidade' criada pelo ser humano para atender a uma necessidade, mas que se torna independente dele e o domina, universalizandose". Ainda segundo Luckesi (2008:18), "os professores se utilizam permanentemente dos procedimentos de avaliação como elementos motivadores dos estudantes, por meio da ameaça". Em seguida, ele completa: "o que predomina é a nota: não importa como elas foram obtidas nem por quais caminhos". Logo, a avaliação, muitas vezes, foi utilizada pelo/a professor/a como mais um dos instrumentos para manter a ordem e a disciplina, pois como era ele/a que media o "valor" de cada aluno/a, a avaliação passou a ser utilizada como meio de punição ou de premiação, características identificáveis até hoje em práticas de muitos/as professores/as.

Embora a atual LDB 9394/96 priorize um caráter qualitativo da avaliação, em seu texto ainda se pressupõe a existência da avaliação quantitativa, pois não se diz textualmente que esta deve ser substituída por aquela, mas tão somente que a avaliação qualitativa deve prevalecer sobre a quantitativa (cf. Artigo V, alínea a da LDB atual). Com base nos dados históricos, é possível perceber o porquê da complexidade de definir o termo avaliação escolar, pois existe uma cultura da avaliação enraizada no cotidiano escolar, constituindo obstáculo para que as novas propostas consigam penetrar e alcançar a sua transformação. 


\section{A definição de "avaliação escolar" nos dicionários}

Nesta seção, recorremos aos dicionários de língua comum e aos dicionários especializados na área de educação para buscar uma melhor compreensão acerca da definição de avaliação e identificar que visões de mundo podem estar embutidas em cada definição, uma vez que entendemos que dicionários não são meros repositórios de palavras, tendo em vista que podem ser resultado, e potencialmente até corroboram, ideologias dominantes.

\subsection{O termo "avaliação escolar" nos dicionários de língua geral}

A palavra "avaliação" aparece no Dicionário Houaiss Eletrônico como:
Avaliação
substantivo feminino
ato ou efeito de avaliar(-se)
1 cálculo do valor de um bem ou de bens
2 Derivação: por extensão de sentido.
valor determinado por quem avalia
Ex.: a avaliação do apartamento atingiu alguns milhares
3 apreciação ou conjectura sobre condições, extensão, intensidade, qualidade etc. de algo
Ex.: < avaliação médica de um paciente > < avaliação do valor literário de um livro $>$
4 verificação que objetiva determinar a competência, o progresso etc. de um profissional, aluno etc.

Na etimologia da palavra "avaliação", nesse mesmo dicionário, aparece o substantivo "valor", que significa "qualidade humana de natureza física, intelectual ou moral, que desperta admiração ou respeito; talento, habilidade, mestria”. Como vimos anteriormente, no cotidiano escolar brasileiro, a palavra "avaliação" durante muito tempo esteve, e ainda está, relacionada a uma ideologia de medida, em que o/a professor/a determina o valor de cada aluno/a. 
Já no Dicionário Aurélio Eletrônico, a palavra "avaliação" aparece com o seguinte significado:

\section{avaliação}

[De avaliar + -ção.]

Substantivo feminino.

1.Ato ou efeito de avaliar(-se).

2.Apreciação, análise.

3.Valor determinado pelos avaliadores:

A avaliação do quadro foi baixa.

Avaliação formativa. 1. Processo de avaliação realizado no decorrer de um programa instrucional visando aperfeiçoá-lo.

Avaliação somativa. 1. Processo de avaliação final de um programa instrucional visando julgá-lo.

Com base nas definições desses dois dicionários de língua comum, é possível perceber a existência de duas características da avaliação. A primeira diz respeito a uma apreciação, em que os/as avaliadores/as determinam o valor de algo ou alguém, tomando um posicionamento positivo ou negativo. Dessa forma, a avaliação é uma decisão de ação. Já a segunda caracteriza o ato de avaliar como um processo.

O Dicionário Houaiss aborda "avaliação" como processo ao falar da verificação do progresso de alguém, fazendo remissão ao ambiente escolar ao abordar alunos/as; porém, ao falar de avaliação, utiliza a palavra "verificação", que apresenta a visão de avaliação enraizada em nossa cultura:

A avaliação, diferentemente da verificação, envolve um ato que ultrapassa a obtenção da configuração do objeto, exigindo decisão do que fazer ante ou com ele. A verificação é uma ação que 'congela' o objeto; a avaliação, por sua vez, direciona o objeto numa trilha dinâmica de ação. (LUCKESI, 2008:93)

O Dicionário Aurélio, ao citar os termos "avaliação formativa" e "avaliação somativa", faz remissão ao contexto de ensino, evidenciando a característica de avaliação como processo dentro da área educacional. Porém, na definição da palavra em si, essa característica não aparece. 
Mesmo não sendo prioridade do verbete abordar a área da educação, os dois dicionários citam algum fator dessa área, mas fica evidenciada a visão de mundo de avaliação como verificação.

\subsection{O termo "avaliação escolar" nos dicionários de especialidade}

Em dicionários especializados da área de educação, o termo "avaliação" não é ainda definido com clareza, pois o que se faz aí é apresentar as diversas discussões acerca do tema. No Dicionário prático de pedagogia (QUEIROZ, 2003:31), o termo "avaliação" é definido como "apreciação, ação de determinar o valor de um trabalho, de uma ação. Consiste na coleta de dados quantitativos e qualitativos"; porém, essa definição apresenta-se vaga, pois não explica quais tipos de dados quantitativos e qualitativos, que tipo de trabalho e ação ou mesmo quais os critérios utilizados para se determinar esse valor. Logo abaixo dessa definição, Queiroz apresenta uma discussão sobre o termo, citando Hoffmann:

O fenômeno avaliação é, hoje, um fenômeno indefinido. Usam o termo com diferentes significados relacionados à prática avaliativa tradicional: prova, nota, conceito, boletim, recuperação, reprovação. Dar nota é avaliar e o registro das notas denomina-se avaliação. Ao mesmo tempo, significados são atribuídos ao termo: análise de desempenho, julgamento de resultado. (...) A avaliação na perspectiva de construção do conhecimento parte de duas premissas: confiança na possibilidade dos educandos construírem suas próprias verdades e valorização de suas manifestações e interesses. Exige do professor uma concepção de criança como sujeito, seres autônomos, intelectual e moralmente. Nessa dimensão, os erros, as dúvidas dos alunos, são considerados episódios altamente significativos. Assim, avaliar é dinamizar oportunidades de ação-reflexão.

(HOFFMANN, 2003 apud QUEIROZ, 2003:32)

Queiroz (2003) apresenta uma característica importante do ato de avaliar que é ação-reflexão, mas ela não o usa explicitamente em sua definição. 
Já o Dicionário brasileiro de educação (DUARTE, 1986:20) informa que avaliação é:

Ato ou efeito de julgar a qualidade, o valor ou a eficiência de algum aspecto do processo educacional, de modo a saber se os alvos desejados ou planejados estão sendo atingidos. Estimativa do trabalho do sistema educacional, como um todo, ou de parte dele. Processo de comparação entre os comportamentos que os alunos manifestam em dado momento e os objetivos propostos. Processo de aferição do rendimento escolar, do qual decorrem resultados que são expressos em notas ou menções. Observação contínua do aluno, em todos os aspectos do seu desenvolvimento: rendimento intelectual (aquisição de conhecimentos), desenvolvimento físico e social. A avaliação deve refletir uma visão global da evolução do aluno. Pode ocorrer que, em dada época, o aproveitamento intelectual seja baixo, mas, simultaneamente, ocorra progresso marcante no desenvolvimento físico e na sociabilidade, também importantes para o processo educativo e o seu julgamento. A fim de facilitar o trabalho de observação, a escola deve dispor de fichas de avaliação, que registram e acompanham o desenvolvimento integral do aluno em toda a sua vida escolar, e o boletim escolar, com os resultados da avaliação periodicamente remetidos à família do aluno.

Com esse dicionário, é possível evidenciar mais uma importante característica da avaliação escolar, que é a observação contínua do desenvolvimento do/a aluno/a, fator primordial para obter um real acompanhamento da sua aprendizagem.

Ao analisar o verbete "avaliação" na obra Termos da Legislação Educacional Brasileira (DUARTE \& DUARTE, 2007), é possível perceber, mais uma vez, o quanto é complexo definir o termo. Essa obra inicia a discussão, destacando, dentre as várias modalidades que compõem o conjunto de práticas avaliativas, a avaliação sistêmica, a avaliação profissional e institucional, e a avaliação escolar.

A avaliação escolar "constitui o conjunto de iniciativas, ações, procedimentos, instrumentos que os/as professores/as desenvolvem para avaliar o processo ensino-aprendizagem" (DUARTE \& DUARTE, 2007). Ela é apresentada sob duas perspectivas teóricas divergentes: a avaliação classificatória e a avaliação formativa. O dicionário mostra 
que a avaliação formativa é considerada a ação central no processo de ensino-aprendizagem, inclusive é a abordagem que predomina na LDB 9394/96. Porém, os autores afirmam que a LDB também traz resquícios de avaliação classificatória, sendo ela uma avaliação "vinculada à noção de medida e à idéia de que é possível aferir, matemática e objetivamente, as aprendizagens escolares. A noção de medida em avaliação supõe a existência de padrões de rendimento (...)" (DUARTE \& DUARTE, 2007, sem página). Já a avaliação formativa:

fundamenta-se em teorias que postulam o caráter diferenciado e singular dos processos de formação humana, nas teorias construtivistas/sociointeracionistas da aprendizagem. Entende que a aprendizagem é uma atividade que se insere no processo global de formação humana, envolvendo o desenvolvimento, a socialização, a construção da identidade e da subjetividade. Assim, a "avaliação formativa" constitui-se numa prática que permite ao professor acompanhar os processos de aprendizagem do aluno com a finalidade de compreender como esse aluno está elaborando seu conhecimento. Nessa abordagem, a preocupação não é registrar os fracassos ou os sucessos do aluno mediante notas ou conceitos, mas entender o significado do seu desempenho para fazer ajustes no processo ensino-aprendizagem. (DUARTE \& DUARTE, 2007, sem página)

Com base nessas definições do termo avaliação, é possível identificar o seu caráter classificatório, formativo, reflexivo, processual, quantitativo e qualitativo. É com base nesses novos posicionamentos que a $\mathrm{LDB}$ e os $\mathrm{PCN}$ buscam modificar a prática da avaliação como "entidade". Analisando esses dicionários, fica perceptível o quanto as definições estão ligadas a determinado posicionamento teórico/ideológico, ou seja, a determinada visão de mundo. É importante analisar e refletir sobre essas questões para se ter consciência da função da avaliação dentro do ambiente escolar, principalmente quando estamos lidando com sociedades, culturas e visões de mundo distintas. 


\section{A educação escolar e "avaliação escolar" em uma comunidade indígena}

A educação escolar indígena no Brasil buscava transformar o/a índio/a em um não-índio/a, modelo de educação que se iniciou com os jesuítas e que perdurou até há pouco tempo como política educacional oficial. Com a criação da "casa do índio", na década de 1960, a educação indígena era abordada por meio de escolas rurais a fim de transformar os indígenas em pequenos produtores rurais. Em 1972, por meio do convênio com o SIL (Summer Institut of Linguistics), adotou-se o ensino bilíngue de transição, que usa as línguas indígenas em posição inferior ao Português, uma vez que nesse método elas só são utilizadas como facilitador para o ensino, realidade até hoje encontrada no Brasil (GOMES, 2009).

$\mathrm{O}$ ensino na escola hoje tende a se fundamentar, ao menos em termos ideais, na diversidade e interculturalidade para a construção de metodologias pluralistas. Para lidar com os conflitos e as riquezas geradas com o relacionamento entre as culturas, é preciso respeito recíproco entre elas (PIMENTEL, 2006).

A comunidade Mundurukú em foco neste trabalho vive no estado do Pará e conta com cerca de 10.000 pessoas, maioria falantes de Mundurukú. Segundo Ramos (2006), o histórico da educação escolar Mundurukú iniciou-se um ano após a instalação da Missão São Francisco em 1911, com o intuito de catequizar a comunidade, oferecendo-lhe, além de alfabetização em Português, cursos de corte e costura, na escola das irmãs, e marcenaria na escola dos padres, em regime de internato. Outras instituições ao longo do tempo ofereceram atividades escolares como o Posto SPI (Serviço de Proteção ao Índio), Missão Batista e SIL; porém, só com a instalação do posto da FUNAI em 1973, a educação teve um caráter laico.

Em 1975, iniciaram-se discussões sobre o ensino bilíngue, surgindo oficinas para criação de material didático e literatura indígena. Somente a partir da década de 1980, a educação escolar Mundurukú teve um caráter mais contínuo. Porém, essa educação sofria, e continua sofrendo, com a falta de verba e professores/ 
as, gerando discussões sobre a necessidade de capacitação de professores/as para tornar possível uma educação diferenciada em língua Mundurukú, língua materna, majoritária na comunidade.

Ainda segundo Ramos (2006), em 1998 foi consolidado o curso de formação de professores/as no II Encontro de Educação Escolar Mundurukú. Em 2004, ocorreu o curso, formando 38 professores/as, o que contribuiu para a troca de experiências e melhor compreensão da realidade Mundurukú, elevando consideravelmente a autoestima do povo. Esse curso contou com o apoio da comunidade, professores/ as e da Coordenação Geral de Educação da FUNAI à época, e depois da Secretaria de Educação do Estado do Pará. Mesmo com esse curso, não foi possível suprir a demanda e nem oferecer a capacitação plena dos/as professores/as. Isso se reflete na ocorrência reiterada de erros do passado em que a qualidade e o caráter diferenciado do ensino são praticamente ignorados no ensino do $6^{\circ}$ ao $9^{\circ}$ ano, espaço em que atuam apenas professores/as não-índios/as, ainda despreparados/as para lidar com uma educação diferenciada e bilíngue. Isso faz que muitos/as alunos/as tenham que se deslocar das aldeias para estudar nos municípios vizinhos, onde seus etnoconhecimentos e cultura não são respeitados.

O censo escolar de 2005 contava 3.280 alunos/as cursando da educação infantil ao ensino fundamental em 40 escolas nas aldeias Mundurukú. Apesar dos índices de reprovação nas séries iniciais, o curso de formação trouxe melhoras. Toda essa realidade gerou a reivindicação de um ensino médio integrado ao ensino profissionalizante, a fim de se evitar o êxodo das aldeias com o não retorno dos/as alunos/as (RAMOS, 2006).

Recentemente, iniciou-se a implantação de escolas de ensino médio em suas aldeias, demanda dos/as próprios/as índios/as, que exigem condições de paridade com a sociedade circundante. Porém, não querendo um ensino comum, propuseram que o ensino médio fosse integrado ao ensino profissionalizante, de modo a oferecer formação, em nível técnico, nas áreas de enfermagem, agroecologia e magistério, áreas hoje de vital importância para a sustentabilidade social, cultural e ambiental do povo mundurukú (FERREIRA \& 
GOMES, 2009). O projeto de Ensino Médio Integrado à Educação Profissional Técnica de Nível Médio do povo Mundurukú ou Projeto Ibaorebu, ao falar da avaliação, registra que ela priorizará o caráter qualitativo e terá a finalidade de diagnosticar problemas, perceber avanços e buscar soluções. A avaliação dos/as alunos/as será focada no desempenho em sua área (magistério, enfermagem ou agroecologia), de acordo com as necessidades da comunidade e de acordo com a sua cultura, sem reprovações, punições e correções que exponham o indivíduo. A avaliação geral será feita com cursistas, professores/as e coordenação, compreendendo as etapas inicial, contínua e final. A avaliação utilizará meios formativos e somatórios com observações do ensino presencial, portifólio individual e autoavaliação.

Em geral, é possível perceber que na educação indígena, atualmente, é incentivada uma avaliação contínua, que respeita o indivíduo; ou seja, é pregada a forma de avaliação que almejamos em nossa sociedade e que é atualmente discutida no campo educacional com o objetivo de transformar a realidade. Porém, ao inserir na prática escolar esse modo de avaliação qualitativa, na comunidade indígena são encontrados entraves burocráticos do nosso sistema educacional, uma vez que nosso sistema ainda está preso a modelos quantitativos de avaliação. É diante desse quadro que o Dicionário Terminológico Escolar busca uma definição do termo avaliação.

\section{O Dicionário Terminológico Escolar Português- Mundurukú/ Mundurukú- Português}

Nesta seção, será apresentado um resumo do projeto Dicionário Terminológico Escolar Português-Mundurukú/Mundurukú-Português: agroecologia, enfermagem e magistério.

A implantação do ensino médio integrado ao profissionalizante nas aldeias Mundurukú do Pará (Projeto Ibaorebu) tem exigido leituras especializadas nas áreas em questão. $\mathrm{O}$ projeto, então, 
tem como finalidade a construção de um dicionário terminológico escolar Mundurukú-Português/ Português-Mundurukú especificamente nas áreas técnicas da formação oferecida. Além de servir como material de apoio no processo de ensino-aprendizagem de índios/as Mundurukú e de ser um meio de manutenção de sua língua, o dicionário também tem como objetivo mostrar o estudo terminológico de línguas consideradas erroneamente inferiores e pouco científicas. Dessa forma, evidencia-se o grande valor daquilo que é produzido nessas comunidades, como os processos médicos, agroecológicos e de ensino (GOMES, 2007). Esse aspecto denota o quão importante é a relação linguagem e sociedade, entendida linguagem não como um substrato exclusivamente biológico, mas como reflexo das relações sociais de poder e cultura.

Por tudo isso, a construção do dicionário está baseada na Teoria Comunicativa da Terminologia (TCT), na Linguística Textual e na Linguística de Corpus (Bevilacqua (1998), Boulanger (1995), Cabré (1998; 1999a, b, c), Carvalho (2005), Gemar (1991), Hoffmann (1998), Kokourek (1991), L'Homme (2004), Sardinha (2004), entre outros). A metodologia para a sua elaboração consiste em: I) estudo sobre o povo Mundurukú; II) estudo sobre Terminologia; III) levantamento bibliográfico do magistério em nível médio; IV) identificação do léxico especializado em textos de nível médio; V) montagem de fichas terminológicas; VI) busca por definições em dicionários especializados; VII) escolha da definição mais apropriada ao nível médio indígena; VIII) proposta de subáreas; IX) discussão da micro e macroestruturas; X) estudos sobre bilinguismos; XI) estudo do referencial básico sobre a língua Mundurukú; XII) trabalhos de campo/ oficinas terminográficas junto aos/às falantes nativos, que se tornam coautores/as e peça fundamental na elaboração do dicionário; e XIII) elaboração do dicionário-piloto.

Os termos e as definições em Mundurukú assim como a aprovação dos termos e conceitos em Português estão sendo fornecidos pelos/as próprios/as indígenas, durante trabalhos de campo e oficinas terminográficas nas aldeias e na Universidade de Brasília. Há a preocupação de não transformar os equivalentes em 
meras traduções, já que esses devem expressar da forma mais fiel possível o entendimento dos Mundurukú acerca dos conceitos, pois, assim como a língua geral, a terminologia também expressa a visão de mundo de uma cultura. Vamos nos focar, na sequência, no termo e no conceito de avaliação escolar.

\section{O termo "avaliação escolar” em Mundurukú, sua morfologia e pragmática}

A palavra correspondente à avaliação escolar na língua Mundurukú é ibuyxijoap ${ }^{3}$. Ao analisar a morfologia da palavra, é possível, a princípio, reconhecer três morfemas, conforme Gomes (2006):

1. $\{i-\}$ ' 3 a pessoa; relacional de não-contiguidade'. Esse prefixo indica que a palavra na qual ele ocorre só existe com relação a outra palavra; em alguma medida, é usado como fator de indeterminação, ou melhor, de indefinição, tendo em vista que a $3^{\text {a }}$ pessoa acaba por assumir esse papel na língua;

2. \{buyxijo\} 'desafiar, enfrentar';

3. $\{$-ap\} 'sufixo nominalizador de paciente, de instrumento, de coisa; de não-agente'.

Diante do primeiro morfema, nos deparamos com o seguinte questionamento: será que o falante reconheceria essa palavra sem o $\{i-\}$ ? Este é um problema que será levado a campo para que os/as próprios/as índios/as nos indiquem a melhor maneira de resolvê-lo no dicionário. $\mathrm{O}$ segundo morfema nos indica um verbo cuja estrutura semântica básica é: [X-agente desafia Y-paciente]. Os exemplos 3 e 4, a seguir, mostram ser este um verbo transitivo em termos de sua valência sintática e semântica. Com o terceiro morfema $\{-a p\}$, dando um caráter semântico de paciente, é possível verificar que, neste caso, o/a desafiante é o/a aluno/a; a prova é o

3. ibuyxijoap: transcrição fonética [ibəj]idzoap]. 
desafiado; a interpretação pressuposta do/a aluno/a é de [+ agente, + controle, + instigador/a, + desencadeador/a do processo] e não o contrário como ocorre com a nossa avaliação tradicional. Isso pode ser verificado nos exemplos dados por falantes nativos/as, recolhidos em trabalho de campo:
1. Hoje tem prova
2. Hoje tem prova de história
3. Eu testei a matemática
4. Eu desafiei o Amâncio

- gasũ kake ibuyxijoap;

- gasũ kake ibuyxijoap historia iap;

- ón matematica osubuyxijo;

- õn Amâncio osubuyxijo.

Dentro da própria morfologia da palavra, é possível identificar a visão de mundo embutida na definição do termo, evidenciando o quanto a concepção Mundurukú de avaliação está mais próxima da que a nossa sociedade almeja. Isso demonstra o quanto podemos aprender com os saberes dessas comunidades e com essas línguas que, erroneamente, são classificadas como inferiores.

\section{A Terminografia no Dicionário Terminológico Escolar Português-Mundurukú/ Mundurukú- Português}

Nesta seção, serão discutidas as decisões tomadas para abordar as acepções do termo avaliação escolar no Dicionário Terminológico Escolar Português-Mundurukú/ Mundurukú-Português para a criação do verbete.

Estudando o termo avaliação escolar, foi possível identificar duas acepções em nossa sociedade. A primeira está amplamente difundida em nossa cultura e foi utilizada durante séculos nas tendências liberais. Dentro dessa visão, a avaliação está relacionada a aprovação e reprovação, que remetem, respectivamente, a ganhar ou perder em um 'jogo escolar', servindo como meio disciplinador mediante ameaças. Assim, a avaliação é utilizada para medir a 
capacidade dos/as alunos/as de forma a verificar a aprendizagem com números, sendo essencialmente quantitativa. De acordo com essa acepção, o/a professor/a apenas classifica os/as alunos/as conforme sua apreciação. A segunda acepção contextualiza-se nas tendências progressistas, tendo se desenvolvido apenas nas últimas décadas do século XX . Atualmente, é a visão de avaliação que os/ as estudiosos/as da Educação buscam aplicar, porém encontram dificuldades, uma vez que a outra visão já está enraizada em nossa cultura e, mesmo conseguindo espaços para difundir a visão progressista nos atuais programas do governo, encontram dificuldades ao colocá-la em prática, já que o governo se utiliza de mecanismos quantitativos ao avaliar os sistemas de ensino. Estamos diante de uma contradição discursiva clara, que precisará ser demonstrada com maiores detalhes em pesquisas que tenham como foco explicitar a relação entre linguagem e sociedade.

Essa segunda concepção apresenta a avaliação como um processo, no qual o/a professor/a faz a diagnose para ter conhecimento do que o/a aluno/a sabe para, com base nesses dados, planejar suas ações com o intuito de desenvolver as habilidades de sua turma para uma melhor aprendizagem. Como o nosso Dicionário é uma obra bilíngue, se faz necessário compreender e acolher a acepção do termo avaliação escolar no universo Mundurukú também. Sendo assim, foi possível verificar que ela está relacionada com a ideia de desafio. O termo em Mundurukú apresenta uma visão mais próxima da segunda acepção citada acima, pois ela enfatiza o/a aluno/a como agente e não como paciente em relação à avaliação. Uma vez que a escola Mundurukú está inserida no sistema educacional brasileiro, o molde da sua avaliação, em certa medida, se enquadra no modelo brasileiro que ainda exige dados quantitativos e ainda se centra na figura do/a professor/a, por enquanto um paradoxo.

Outros aspectos que fazem os Mundurukú terem contato com o nosso modo de avaliar são o fato de haver professores/as não-índios/ as nas aldeias e o fato de alunos/as indígenas estudarem fora da aldeia também, mantendo contato com a nossa forma de avaliar; por isso, 
conhecem bem o termo "prova", mas estabelecem uma relação distinta da nossa, uma vez que são eles que a desafiam e não o contrário.

Logo, a proposta de verbete para avaliação escolar mais próxima dessa complexa realidade seria:

avaliação ibuyxijoap s.f. O.P. 1. Processo de acompanhamento/ medição do desenvolvimento dos/as alunos/as no seu dia-a-dia, dentro e fora da escola, para que o/a professor/a possa planejar melhor as suas ações. 2. Desafio a ser vencido. Hoje tem prova $\mathbf{g} a s \tilde{u}$ kake ibuyxijoap; Hoje tem prova de historia gasũ kake ibuyxijoap historia iap; eu testei a matemática on matematica osubuyxijo; eu desafiei o Amâncio on Amâncio osubuyxijo. <NG: Entre os Mundurukú, o conceito de avaliação é associado com o conceito de desafio. $>\rightarrow$ prova; desafio; teste; experimento.

Uma vez que o dicionário servirá como material didático dos cursos e por estar garantido por lei o ensino bilíngue, ele busca abordar as duas línguas de forma igual. Tendo conhecimento da relação de diglossia vivida pelos falantes, o projeto adota a postura de um bilinguismo pluralista e funcional (GOMES, 2009), dando apoio para a elevação do status da língua Mundurukú. Por isso, o verbete contém entradas nas duas línguas, com idêntica formatação. Em seguida, apresentamos a categoria gramatical ${ }^{4}$ do verbete em Português e a subárea ${ }^{5}$ à qual o termo pertence e que definimos em itálico; no caso do verbete acima, a subárea O.P. refere-se à organização pedagógica.

Como já ficou evidenciada a existência de uma tensão entre o sistema educacional brasileiro com a sua visão de mundo sobre avaliação escolar e o que se quer para o povo Mundurukú idealmente, partindo da sua visão de mundo sobre o termo, então

4. A categoria gramatical é informada para facilitar a compreensão e indicar sua função gramatical no uso da língua, uma vez que os consulentes aprendem o Português como segunda língua.

5. As subáreas propostas são: abordagens de ensino-aprendizagem (AEA), corpo escolar (CE), organização escolar (OE), organização pedagógica (OP), recursos didáticos $(\mathrm{RD})$ e leis $(\mathrm{L})$. 
ficou estabelecido para o verbete o uso de duas acepções. A primeira acepção é a tradicionalmente dada na literatura formal, externa, na nossa cultura, tendo como ponto de apoio a nossa história escolar e a nossa atual legislação. Utilizamos "acompanhamento/ medição" para abranger os dois significados identificados em nossa sociedade a depender da tendência teórica seguida, significados esses com os quais os Mundurukú já têm contato. Por isso, mantivemos as duas visões de mundo em uma única acepção, mas aplicamos o recurso da barra para separá-las. A segunda acepção é a própria concepção dos/as alunos/as Mundurukú do projeto Ibaorebu, tendo sido discutida e formulada em trabalho de campo, além de ser verificada na documentação relativa à escola Mundurukú.

O texto da definição busca ser o mais simples e direto possível, pois o público-alvo, mesmo sendo em grande maioria bilíngue, ainda não domina o Português nos mais elevados níveis de Letramento. Os exemplos foram coletados em trabalho de campo. Eles vêm após a acepção e têm o objetivo de completá-la, e sua separação se dá pelo uso do ponto-e-vírgula. No original, optamos pelo uso de cores nos exemplos para enfatizá-los, como meio facilitador da compreensão, uma vez que foram retirados de contextos de uso das línguas. A nota geral nesse verbete se fez necessária para justificar a segunda acepção. Outra escolha consciente no campo da nota geral é que evitamos elipses no texto em Português a fim de se ter mais clareza. Por último, encontram-se as remissões para que os/as consulentes possam buscar outros termos que completem a compreensão da definição do termo, ficando em negrito para destacar.

É importante perceber o quanto cada decisão tomada acerca da macro e da microestrutura do dicionário deve ser analisada, focando no uso do nosso público-alvo, a fim de facilitar o seu aprendizado e a compreensão sobre os conteúdos estudados no Ensino Médio profissionalizante. O verbete como um todo já foi levado para área indígena e, após ampla discussão e modificação na oficina terminográfica, foi aceito pelo povo. 


\section{Considerações finais}

O trabalho terminológico envolvendo duas línguas é bastante rico e complexo, pois cada língua expressa a visão de mundo do povo que se comunica por meio dela. Tendo conhecimento da relação diglóssica vivida em boa parte das comunidades Mundurukú do Pará, são de fundamental importância projetos que adotem a postura de um bilinguismo funcional e pluralista, a fim de dar apoio à elevação do status da língua dominada para que ela chegue às funções de poder e, futuramente, possa atingir, quem sabe, um ideal de planificação linguística.

O Dicionário Terminológico Escolar Português-Mundurukú/ Mundurukú- Português, além de contribuir para o aprendizado dos/ as alunos/as, facilitando a comunicação, propõe evitar a adoção indiscriminada de termos do Português para o Mundurukú para os quais já existam equivalentes e incentivar a criação de neologismos. Dessa forma, pretende-se contribuir para a preservação da língua, da cultura e da identidade do povo Mundurukú, reconhecendo o valor da sua língua materna. Por isso, se faz necessário aprofundar as discussões feitas na criação de cada verbete - como mostramos aqui em relação ao verbete avaliação escolar -, tomando o devido cuidado em cada escolha feita, pois o dicionário não aborda apenas a nossa visão de mundo, mas principalmente buscamos dar o mesmo espaço para o conhecimento do povo Mundurukú.

É muito complexo trabalhar com culturas distintas, porém ao mesmo tempo é enriquecedor, pois percebemos o quanto podemos aprender com esse saber diferente do nosso, compreendendo que o grande erro está em avaliar uma cultura e uma língua como inferior a outra. Só é possível perceber como funciona uma língua desde os seus níveis mais lexicais até os mais gramaticais quando a pesquisa linguística leva em conta a relação intrínseca entre linguagem e sociedade. $\mathrm{O}$ conceito predominante de avaliação escolar nasce no século XVI e praticamente não mudou em termos reais até hoje (século $\mathrm{XXI})$, apesar de inúmeras propostas teóricas que pretendem mudar o eixo do nosso sistema educacional, para transformá-lo em um sistema 
de aprendizagem significativa. A maior expectativa deste artigo é mostrar como a ideologia dominante ao longo do tempo manteve a avaliação escolar como uma forma de manutenção do status quo. Também valioso aqui foi mostrar como uma comunidade indígena brasileira pode nos dar um contraexemplo a essa ideologia dominante a partir da sua própria visão educacional.

Recebido em: março de 2012 Aprovado em: abril de 2012 dioney98@unb.br taniatbf@gmail.com

\section{Referências bibliográficas}

ARANHA, M.L. de A. História da educação. 1. ed. São Paulo: Moderna,1989. BEVILACQUA, C. R. "Unidades fraseológicas especializadas: novas perspectivas para sua identificação e tratamento". Organon. v. 12, n. 26. Porto Alegre: 1998, pp.119-132.

BOULANGER, J.C. Présentation: images et parcours de la socioterminologie. Meta, v, 40, n.2, 1995, pp.195-205.

BRASIL. Lei no 9.394, de 20 de dezembro de 1996. Lei de Diretrizes e Bases para a educação nacional.

BRASIL. Secretaria de Educação Fundamental. Parâmetros Curriculares Nacionais. Brasília: Ministério da Educação, 1997.

BRASIL. Referencial curricular nacional para as escolas indígenas. 2002.

CABRÉ, M.T. La terminología: representación y comunicación. Barcelona: Universitat Pompeu Fabra,1998.

. Principios teóricos sobre la terminologia,ámbito y unidades de estudio. Sumario de principios y consecuencias metodológicas. La terminologia científico-técnica: reconocimiento, análisis y extracción de información formal y semántica. (Informe DGES PB-96-0293). Barcelona: Universitat Pompeu Fabra, Institut Universitari de Lingüística Aplicada, 1999a. 
. "Variació per tema. El discurs especialitzat o la variació funcional determinada per la temática: noves perspectives". Revista Internacional de Filología. Caplletra: Valencia, 1999b, pp.173-194.

- Terminologia: Representación y comunicación. Elementos para una teoría de base comunicativa y otros artículos. Sèries Monografies, 3. Barcelona: Universitat Pompeu Fabra, Institut Universitari de Lingüística Aplicada, 1999c.

CARVALHO, E. A. Colocações conceituais e lexicais em linguagens de especialidade. Dissertação de Mestrado, Brasília, UnB, 2005.

COMIS. D. A função social da escola e da avaliação da aprendizagem. Dialogia, São Paulo, v. 5 p. 135- 144, 2006.

Dicionário Eletrônico Aurélio, 1999, V. 3.0.

Dicionário Eletrônico Houaiss, 2009, V. 3.0.

DUARTE, A. C; DUARTE, M. R. T. (org). Termos da Legislação Educacional Brasileira. Belo Horizonte: UFMG, 2007.

DUARTE, S. G. Dicionário brasileiro de educação. Rio de Janeiro: Edições Antares: Nobel, 1986.

FERREIRA, T. B \& GOMES, D. M. Construindo o Dicionário Terminológico Escolar Português-Mundurukú /Mundurukú-Português: Magistério. 2009.

GÉMAR, J. C. "Terminologie, langue et discours juridiques. Sens et signification du langage du droit. Meta, v.36, n.1, 1991.pp.275-286.

GHIRALDELLI: J. História da educação brasileira. 4.ed. São Paulo: Cortez, 2009.

GOMES, D. M. Estudo morfológico e sintático da língua Mundurukú (Tupí). Tese de doutorado. Universidade de Brasília. Programa de Pós-Graduação em Linguística. Brasília, 2006.

GOMES, D. M. Dicionário Terminológico Escolar Português-Mundurukú / Mundurukú-Português: Agrofloresta, Enfermagem e Magistério. 2007

GOMES, D. M. "Por uma educação bilíngue pluralista e funcional: os espaços do mundurukú (tupí) e do português no âmbito da terminologia escolar indígena". In: Libro de Actas II Encuentro de Lenguas Indígenas Americanas y II Simposio Internacional de Lingüística Amerindia Asociación de Lingüística y Filología de América Latina (ALFAL) 17-19 de septiembre de 2009. Resistencia: CONICET, 2009. 
HOFFMANN, L. Llenguatges d'especialitat. Selecció de textos. In: BRUMME, J. (dir.) Barcelona: IULA/UPF, 1998.

KOCOUREK, R. (1991). “Textes et termes”. Meta, v.36. n.1, pp.71-75.

L'HOMME, M.C. La terminologie: principes et techniques. Montréal: Les Presses de l’Univertsité de Montréal, 2004.

LIBÂNEO, J.C. Didática. São Paulo: Cortez, 1994.

LUCKESI, C.C. Avaliação da aprendizagem escolar. 19.ed. São Paulo: Cortez, 2008.

QUEIROZ, T. D. (org.). Dicionário Prático de Pedagogia. 1. ed. São Paulo: Rideel, 2003.

PIMENTEL DA SILVA, M. S. "As línguas indígenas na escola: da desvalorização à revitalização.” In Revista do Programa de Pós-Graduação em Letras e Linguística/ Faculdade de Letras. V. 18, n 2. Goiânia: Programa de Pós-Graduação em Letras e Linguística/ Faculdade de Letras, pp. 381-395, 2006.

RAMOS, A. Ensino Médio Integrado à Educação Profissional Técnica de Nível Médio para Habilitação de Técnico em Agrofloresta, Enfermagem ou Magistério: projeto Munduruku. 2006.

RIBEIRO, M.L.S. História da educação brasileira. 12.ed. São Paulo: Cortez, 1992.

SARDINHA, T. B. Lingüística de Corpus. Barueri, SP: Manole, 2004.

SOUZA, S. M. Z. L. "Avaliação da aprendizagem: ênfase nas presentes pesquisas no Brasil de 1930 a 1980". Cadernos de Pesquisa, São Paulo: Fundação Carlos Chagas, n. 94: 44-48, 1995. 